\title{
THE SURVIVAL OF PREMATURE INFANTS DEPENDING ON THE LEVEL OF MEDICAL ASSISTANCE
}

\author{
Larisa Crivceanscaia ${ }^{1}$, Maria Stamatin ${ }^{2}$, Mihai Stratulat ${ }^{1}$ \\ ${ }^{I}$ Department of Pediatrics and Neonatology, "N. Testemitanu" Medical University \\ ${ }^{2}$ Department of Mother and Child Medicine, \\ "Gr. T. Popa" University of Medicine and Pharmacy, Iasi
}

\begin{abstract}
Worldwide, premature birth is the main cause of infant mortality and a significant cause of human potential loss of premature survivors for the next stages of life.

Purpose. To determine the rate of premature infants survival depending on the level of medical assistance and the main risk factors involved in the death of preterm infants with gestational age less than 34 weeks.

Materials and methods. We included in the study 750 preterm newborns divided into three groups as follows: group 1 - 476 premature newborns born in IMSP IMsC, Chisinau (level III maternity); group 2 - 240 premature infants transferred by the AVIASAN service from level I and II maternities to the level III unit and group $3-34$ premature babies from IMSP IMsC Chisinau that received surfactant administered by the LISA method (Less Invasive Surfactant Administration). We performed a complex analysis of the risk factors for death and the positive impact of highly specialised care on survival. The data was analysed using SPSS V.21 software (IBM Statistical Package for the Social Sciences, Chicago, Illinois).

Results. The survival rate at 78 days of life was significantly higher in the newborns from the level III maternity that received LISA therapy (93.3\%), compared to those in group $1(78.2 \%)$ and group $2(78.9 \%)$ respectively. Conclusions. The survival of premature infants is a multifactorial problem. The main factor that determines the rate of death for these infants is respiratory distress syndrome (RDS), followed by birth weight (BW), gestational age (GA), resuscitation method, bronchopulmonary dysplasia (BPD) and last but not least by the level of maternity where the infants were born. These factors might be considered predictive for death of preterm newborns with gestational age less than 34 weeks.
\end{abstract}

Keywords: newborn, survival, mortality, premature

\section{INTRODUCTION}

According to the Report of the WHO Global Action on premature birth "Born too soon" from 2012, more than $10 \%$ of babies are born prematurely, what means 15 million preemies yearly (WHO "Born too soon", 2012). Moreover, each year, over one million children die of complications related to premature birth. Many survivors remain with scars for life, including communication difficulties, impaired vision and hearing (ACOG Committee Opinion No. 475, 2011; Copetti \& Cattaross, 2007; Onland et al., 2011).

Worldwide, premature birth is the main cause of infant mortality and a significant cause of human potential loss of premature survivors for the next stages of life (Stratulat et al., 2013).
More than $60 \%$ of premature births occur in Africa and South Asia. USA, Brazil, India and Nigeria are in the top 10 countries where the rate of premature births forms the majority of the global incidence of prematurity. The average incidence of premature births for countries with low economic level is around $12 \%$ compared to $5-18 \%$ for high economic level countries. Over $80 \%$ of premature births occur at 32-37 weeks of gestation and most of these babies can survive if essential neonatal care is given. Moreover, $75 \%$ of deaths can be prevented without using intensive neonatal care measures.

\section{PURPOSE}

The purpose of this study was to determine the rate of survival for premature infants depending on

Corresponding author:

Maria Stamatin, "Gr. T. Popa" University of Medicine and Pharmacy, 16 University Street, lasi

E-mail: maria.stamatin@yahoo.com 
the level of medical assistance and the main risk factors involved in the death of preterm infants with gestational age less than 34 weeks.

\section{MATERIAL AND METHOD}

The cases included in the study were divided into three groups as follows: group $1-476$ premature newborns born in IMSP IMsC, Chisinau (level III maternity); group 2 - 240 premature infants transferred by the AVIASAN service from level I and II maternities to the level III unit and group 3 - 34 premature babies from IMSP IMsC Chisinau receiving surfactant administered by LISA. For each group we analysed the survival rate and length, the survival rate correlated both to GA and RDS and also the risk factors for death (GA, BW, resuscitation, RDS severity and the level of the maternity in which the infants were born). The severity of RDS was assessed by the Silverman score as follows: a score $\leq 3-$ mild RDS, a score $=4-6-$ moderate RDS, a score $\geq 7$ - severe RDS.

The data was analyzed using SPSS V.21 software (IBM Statistical Package for the Social Sciences, Chicago, Illinois). Continuous variables with normal distribution were expressed as mean \pm standard deviation, and continuous variables without normal distribution were expressed as median (min-max). Categorial variables were expressed as absolute and relative frequency. For continuous variables, homogeneity of variance was checked by Levene Test and, depending on the result, the Kruskal Wallis test was applied. For categorical variables, the Maximum Likelihood Chi-Square test and Spearman Rank R correlation test were applied for comparison. For survival analysis we used the Kaplan-Meier method, and to compare the survival rate, we used Cox's F-Test and Log-Rank Test. Significance level (p) was considered to be 0.05 .

\section{RESULTS}

The survival rate was significantly higher in the newborns from the level III maternity that were managed with LISA. For their group the estimated survival rate was $93.3 \%$ at 78 days of life, while at the same time the survival rate in group 1 (level III) was $78.2 \%$ and respectively $78.9 \%$ for the infants transferred from level I or II units. In the case of premature neonates born at the level III maternity, the survival rate decreased significantly after 78 days of life, reaching $23.47 \%$ at 109 days. This aspect might be explained by the complex pathology of these newborns. After 78 days of life, the sur- vival rate in the second group is maintained at $78.9 \%$ (Table 1 ).

TABLE 1. Results for survival rate evaluation in study groups

\begin{tabular}{|l|c|c|c|}
\hline $\begin{array}{l}\text { Time limit } \\
\text { (evaluation } \\
\text { moment) }\end{array}$ & $\begin{array}{c}\text { \% cumulative } \\
\text { survival }\end{array}$ & $\begin{array}{c}\text { \% cumulative } \\
\text { survival }\end{array}$ & $\begin{array}{c}\text { \% cumulative } \\
\text { survival }\end{array}$ \\
\hline [days] & $\begin{array}{c}\text { group 1 - } \\
\text { level III }\end{array}$ & $\begin{array}{c}\text { group 2 - } \\
\text { level I, II }\end{array}$ & $\begin{array}{c}\text { group 3 - } \\
\text { level III-LISA }\end{array}$ \\
\hline $\mathbf{1 . 0 0 0 0 0 0}$ & 100.0000 & 100.0000 & 100.0000 \\
\hline $\mathbf{1 6 . 4 4 4 4 4}$ & 90.4651 & 88.1235 & 93.3333 \\
\hline $\mathbf{3 1 . 8 8 8 8 9}$ & 88.4696 & 86.6171 & 93.3333 \\
\hline $\mathbf{4 7 . 3 3 3 3 4}$ & 86.0704 & 82.0583 & 93.3333 \\
\hline $\mathbf{6 2 . 7 7 7 7 8}$ & 83.6287 & 78.9022 & 93.3333 \\
\hline $\mathbf{7 8 . 2 2 2 2 2}$ & 78.2333 & 78.9022 & 93.3333 \\
\hline $\mathbf{9 3 . 6 6 6 6 6}$ & 70.4099 & 78.9022 & \\
\hline $\mathbf{1 0 9 . 1 1 1 1}$ & 23.4700 & 78.9022 & \\
\hline $\mathbf{1 2 4 . 5 5 5 5}$ & & 78.9022 & \\
\hline $\mathbf{1 4 0 . 0 0 0 0}$ & & 78.9022 & \\
\hline & Cox'sF-Test & $\mathrm{F}=10.863358$ & $\mathrm{p}=0.012169$ \\
\cline { 2 - 4 } & Log-Rank Test & $\begin{array}{c}\text { Test statistic } \\
7.9137233\end{array}$ & $\mathrm{p}=0.036086$ \\
\hline
\end{tabular}

Due to the fact that the survival does not present an even distribution and is not normal, the comparison of the survival time was carried out on the basis of the median (Graphic 1, Table 2).

The survival time was significantly higher (HKruskal-Wallis $=15.93, p<<0.01)$ in the group of premature infants born at level III and managed with LISA (39.4 $\pm 13.5 \mathrm{DS}$ ) (Graphic 2, Table 2). This is an indication that this method can be successfully used in the respiratory management of preterm newborns, with the possibility to avoid intubation. According to a study, the optimal gestational age for this method is 28-32 weeks of gestation. As well, this study showed that this method is as effective as conventional mechanical ventilation in reducing and maintaining a constant $\mathrm{FiO} 2$ after surfactant administration through the endotracheal tube (Aguar et al., 2014). Respectively, considering the more pronounced side effects of mechanical ventilation, the LISA method gets more and more interest in the NICUs.

Gestational age was significantly lower in newborns that died, estimated at 27.6 weeks \pm 2.1 in group 1 (level III), 28.5 weeks. \pm 0.7 in group 3 (level III - LISA) and 29.6 weeks \pm 2.9 in group 2 (levels I and II) (Graphic 3, Table 3, Table 4).

The severity of RDS is significantly linked with deaths, as $70.73 \%$ of the deceased infants had severe RDS (Graphic 4, Table 5). In infants without RDS and in cases with mild forms of RDS, the mortality is about $7.53 \%$, with a slight increase in moderate forms of RDS up to $12.32 \%$, while in se- 


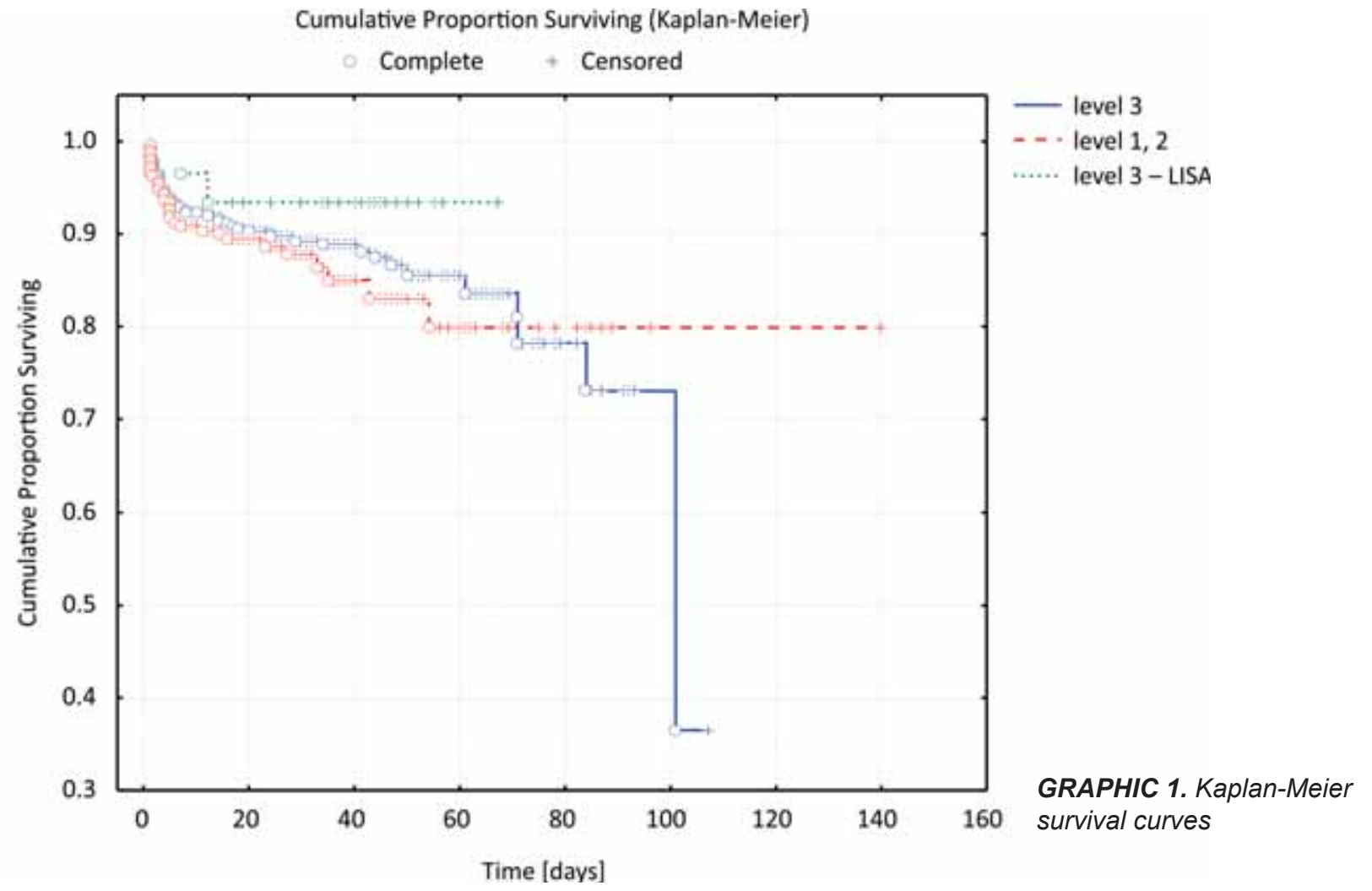

TABLE 2. Statistical indicators of survival time in the study groups

\begin{tabular}{|l|c|c|c|c|c|c|c|c|c|c|}
\hline Group & \multirow{2}{*}{$\begin{array}{c}\text { Mean } \\
\text { Surv. Time }\end{array}$} & \multicolumn{2}{|c|}{ Mean } & \multirow{2}{*}{ Std. dev } & Std.er & Min & Max & Q25 & Median & Q75 \\
\cline { 3 - 9 } & $\mathbf{1 6 . 1}$ & 9.9 & 22.2 & 23.2 & 3.1 & $\mathbf{1 . 0}$ & $\mathbf{1 0 1 . 0}$ & 2.0 & $\mathbf{5 . 0}$ & 18.0 \\
\hline Level III & $\mathbf{1 0 . 5}$ & 5.4 & 15.6 & 13.9 & 2.5 & $\mathbf{1 . 0}$ & $\mathbf{5 4 . 0}$ & 1.0 & $\mathbf{5 . 0}$ & 14.0 \\
\hline $\begin{array}{l}\text { Level III } \\
\text {-LISA }\end{array}$ & $\mathbf{1 0 . 5}$ & -22.3 & 41.3 & 3.5 & 2.5 & $\mathbf{7 . 0}$ & $\mathbf{1 2 . 0}$ & 7.0 & $\mathbf{9 . 5}$ & 12.0 \\
\hline
\end{tabular}

Box Plot of hospital days grouped by

06_BD_externare.sta $11 v^{*} 750 c$

Include condition: deaths

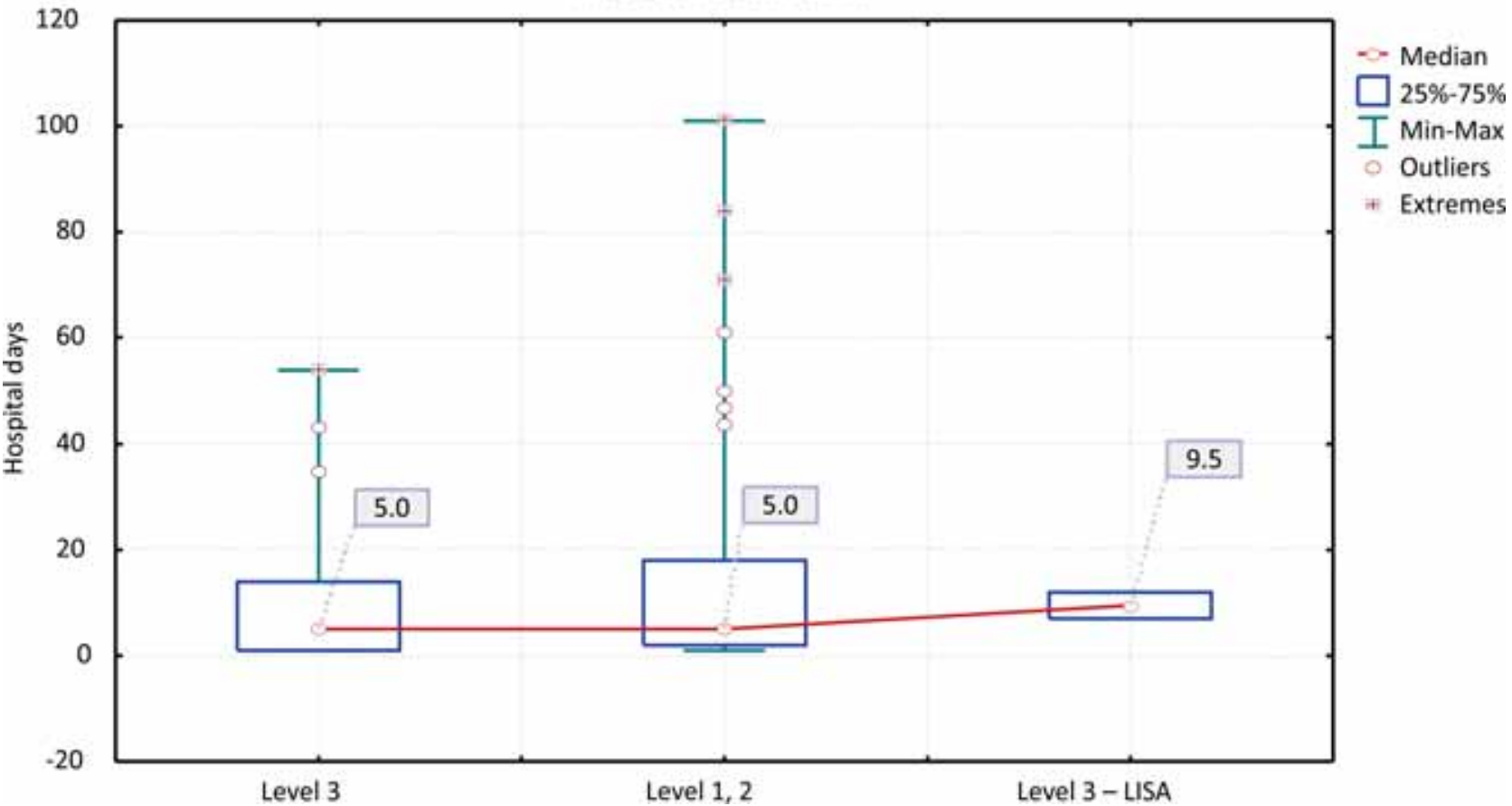

GRAPHIC 2. The mean survival in the study group 
Plot of Means and Conf. Intervals (95.00\%)

lot 1: $F(1,474)=82.6230, p=0.0000 ; K W-H(1,476)=63.0041, p=0.0000$

lot 2: $F(1,238)=8.6102, \mathrm{p}=0.0037 ; \mathrm{KW}-\mathrm{H}(1,240)=5.8749, \mathrm{p}=0.0154$

lot 3: $F(1,32)=0.3062, p=0.5839 ; K W-H(1,34)=0.3583, p=0.5495$

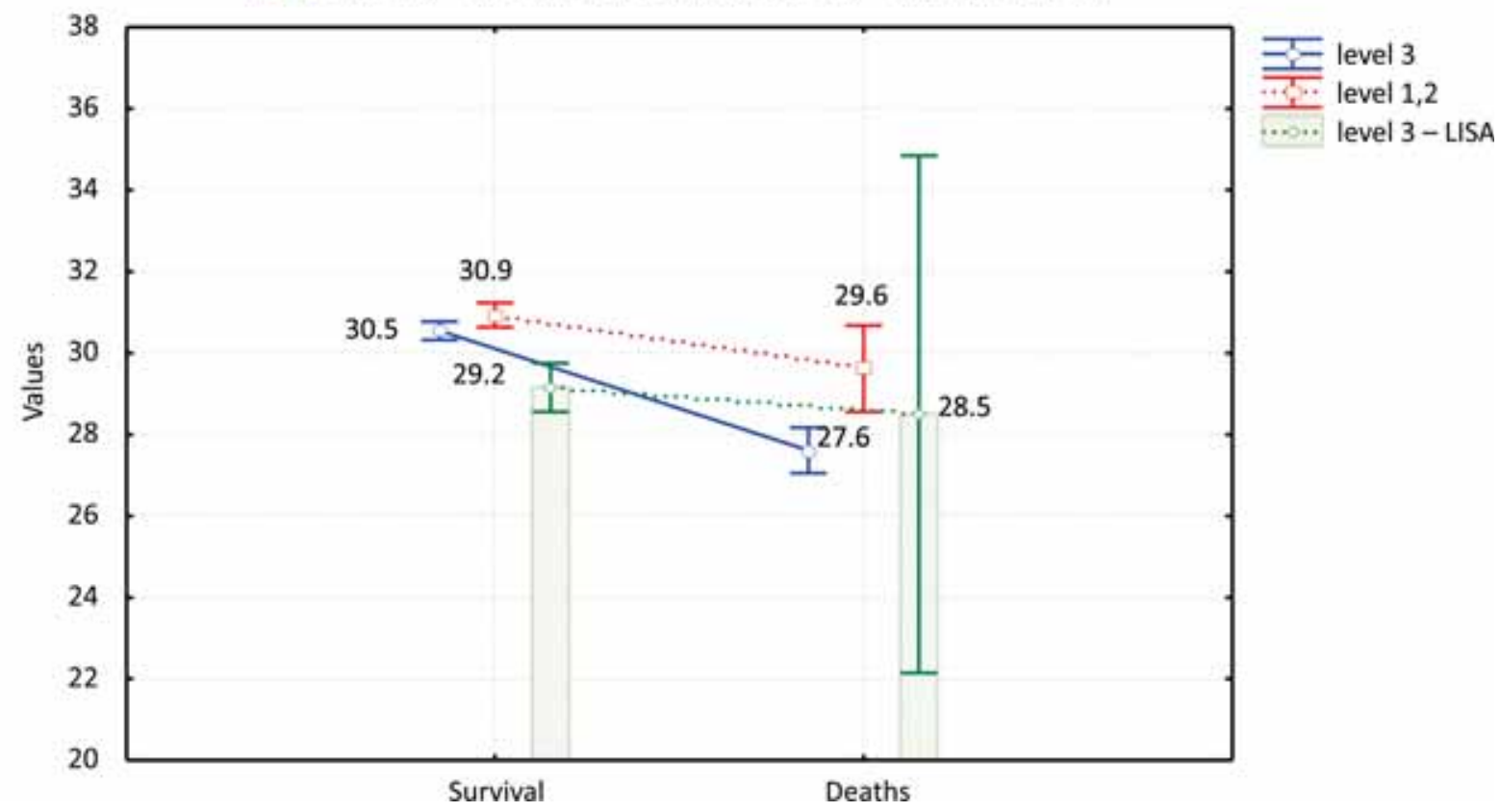

GRAPHIC 3. Mean gestational age in the study group

TABLE 3. Statistical indicators of gestational age in the study groups vs. survival

\begin{tabular}{|c|c|c|c|c|c|c|c|c|c|c|c|}
\hline \multirow{2}{*}{ Group } & & \multirow{2}{*}{$\begin{array}{c}\text { Mean } \\
\text { VG }\end{array}$} & \multicolumn{2}{|c|}{ Mean } & \multirow{2}{*}{ Std.std } & \multirow{2}{*}{ Std.er } & \multirow{2}{*}{ Min } & \multirow{2}{*}{ Max } & \multirow{2}{*}{ Q25 } & \multirow{2}{*}{ Median } & \multirow{2}{*}{ Q75 } \\
\hline & & & $-95 \%$ & $+95 \%$ & & & & & & & \\
\hline \multirow{2}{*}{ Level III } & surv. & 30.5 & 30.3 & 30.8 & 2.3 & 0.1 & 24.0 & 34.0 & 29.0 & 31.0 & 32.0 \\
\hline & Death & 27.6 & 27.1 & 28.2 & 2.1 & 0.3 & 23.0 & 34.0 & 26.0 & 28.0 & 29.0 \\
\hline \multirow{2}{*}{ Level I, II } & surv. & 30.9 & 30.6 & 31.2 & 2.2 & 0.2 & 24.0 & 34.0 & 30.0 & 31.0 & 33.0 \\
\hline & Death & 29.6 & 28.6 & 30.7 & 2.9 & 0.5 & 25.0 & 34.0 & 27.0 & 29.0 & 32.0 \\
\hline \multirow{2}{*}{ Level III -LISA } & surv. & 29.2 & 28.6 & 29.8 & 1.6 & 0.3 & 26.0 & 32.0 & 28.0 & 29.0 & 30.0 \\
\hline & Death & 28.5 & 22.1 & 34.9 & 0.7 & 0.5 & 28.0 & 29.0 & 28.0 & 28.5 & 29.0 \\
\hline
\end{tabular}

TABEL 4. Gestational age vs. Survival comparison

\begin{tabular}{|l|c|c|}
\hline Test & $95 \% \mathrm{Cl}$ & $\mathbf{p}$ \\
\hline $\begin{array}{l}\text { Levene Test of Homogeneity of } \\
\text { Variances }\end{array}$ & 3.773988 & 0.002212 \\
\hline Kruskal-Wallis Test & 22.46461 & 0.000000 \\
\hline
\end{tabular}

vere forms of RDS the mortality rate can be as high as $70.73 \%$. This shows that in severe forms of RDS the mortality rate is quite high, despite of all the progress in the management and care of premature neonates. Nevertheless, the incidence of RDS decreases with the increasing of the gestational age (Stevenson et al., 2015).

A multivariate analysis generated a model to define significant predictive factors that influence premature death of newborns with gestational age less than 34 weeks (Graphic 5). For the study we used the "ENTER" method, in which all predictive factors were included in a single step. HosmerLemeshow test results $\left(\chi^{2}=6.51, \mathrm{df}=6, \mathrm{p}=0.314\right.$, $95 \% \mathrm{CI})$, indicate that the model is appropriate. The $\mathrm{R}^{2}$ Nagelkerke value was 0.679 , suggesting that the model is very predictive, values are statistically significant and that the effect is high.

The value of the correlation coefficient $\mathrm{R}$ of 0.761 shows a high correlation between predictive variables simultaneously with the independent variable (resuscitation). The value for $\mathrm{R}^{2}(0.579)$ indicates that in $57.9 \%$ cases survival was significantly influenced by independent variables introduced in study (Table 6, Table 7). 


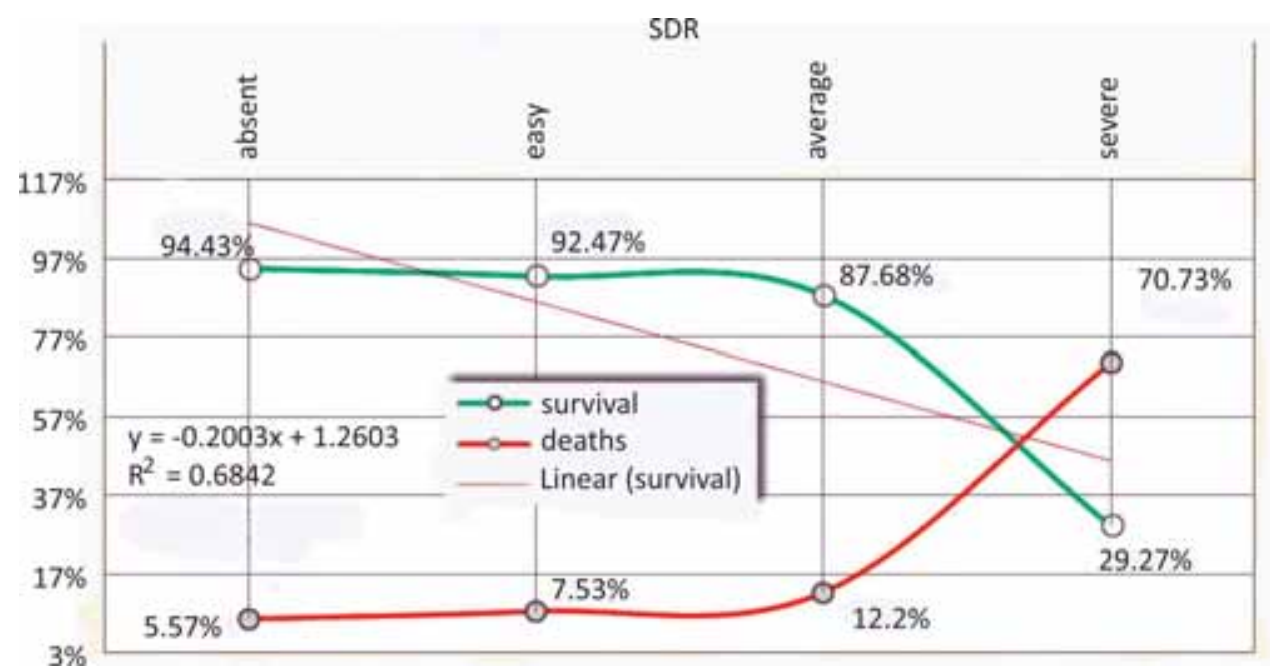

GRAPHIC 4. RDS severity in the studied groups vs. deaths

TABLE 5. RDS severity in the studied groups vs. deaths

\begin{tabular}{|l|c|c|c|c|c|}
\hline & Survival & & Death & & Totals \\
\hline Groups RDS & $\mathbf{N}$ & $\%$ & $\mathbf{N}$ & $\%$ & \\
\hline Absent & 271 & $94.43 \%$ & 16 & $5.57 \%$ & 287 \\
\hline Mild & 135 & $92.47 \%$ & 11 & $7.53 \%$ & 146 \\
\hline Moderate & 242 & $87.68 \%$ & 34 & $12.32 \%$ & 276 \\
\hline Severe & 12 & $29.27 \%$ & 29 & $70.73 \%$ & 41 \\
\hline Totals & 660 & & 90 & & \\
\hline M-L Chi-square & & 93.28579 & $\mathrm{p}=0.0000$ \\
\hline \multicolumn{7}{|l|}{ Corelation coeficient (Spearman Rank R) } & .5810946 & $\mathrm{p}=0.0000$ \\
\hline
\end{tabular}

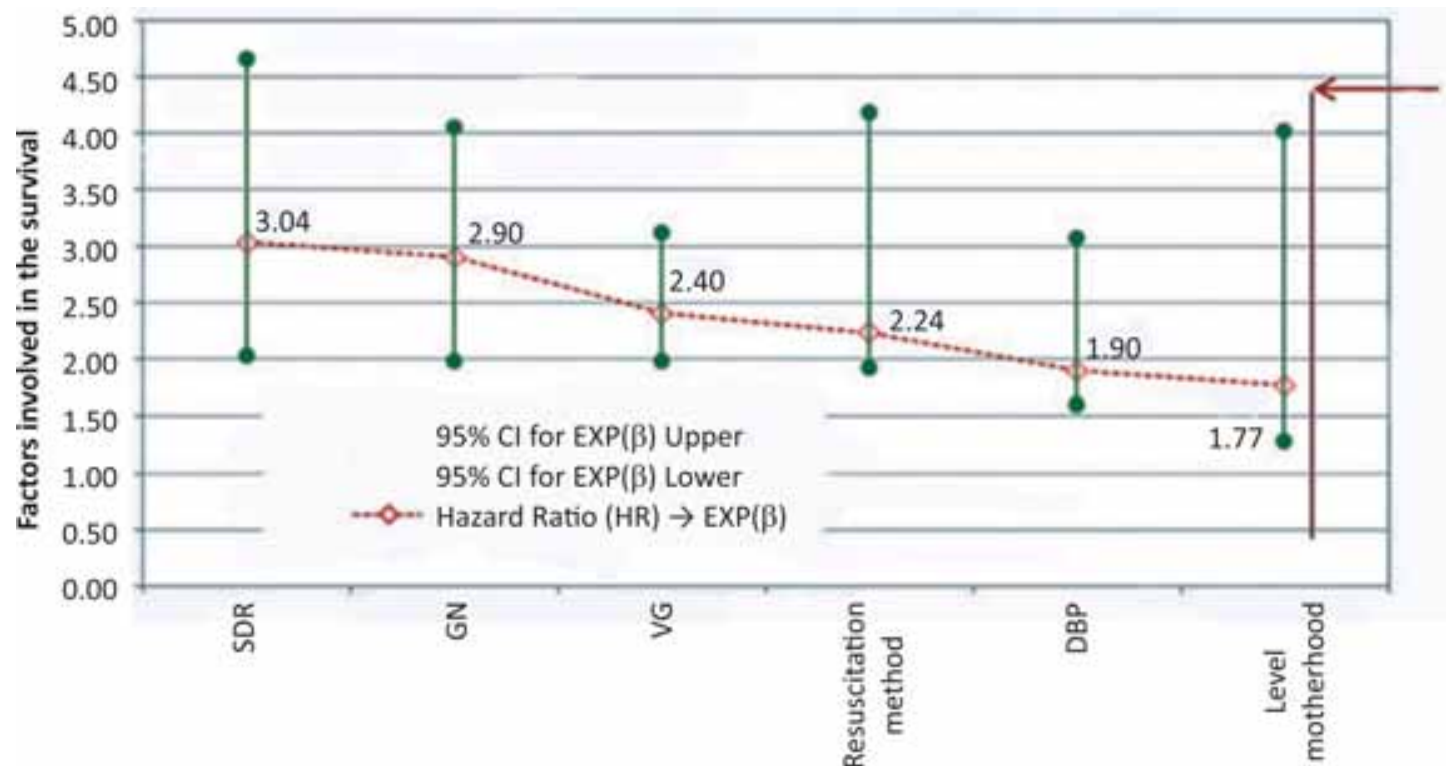

GRAPHIC 5. Hazard Ratio (HR) values in the multivariate analysis of risk factors in premature newborns death

TABLE 6. Test to verify the validity of the model ("ENTER" method)

\begin{tabular}{|l|c|c|c|}
\hline \multicolumn{4}{|c|}{ Hosmer and Lemeshow Test } \\
\hline Step & $\begin{array}{c}\text { Chi-square } \\
\left(\text { Testul } \chi^{2}\right)\end{array}$ & $\begin{array}{c}\mathrm{df} \\
\text { (degree of free) }\end{array}$ & Sig.p \\
\hline 1 & 6.517 & 6 & 0.3147 \\
\hline
\end{tabular}

TABLE 7. Verification of the model's predictive power

\begin{tabular}{|c|c|c|c|c|}
\hline \multicolumn{4}{|c|}{ Model Summary } & \multirow[b]{2}{*}{$\begin{array}{l}\text { Std. Error of } \\
\text { the Estimate }\end{array}$} \\
\hline & $\mathrm{R}$ & R Square & $\begin{array}{l}\text { Adjusted R } \\
\text { Square }\end{array}$ & \\
\hline 1 & 0.761 & 0.5791 & 0.607 & 0.00217 \\
\hline
\end{tabular}


Multiple regression results demonstrate that the severity of the respiratory distress syndrome is the most important risk factor for death $(\mathrm{HR}=3.04 \rightarrow$ 95\%CI: 2.02-4.65) followed by birth weight $(\mathrm{HR}=2.901 \rightarrow 95 \% \mathrm{CI}: 2.31-4.05)$, gestational age $(\mathrm{HR}=2.40 \rightarrow 95 \% \mathrm{CI}: 1.98-3.12)$, resuscitation method $(\mathrm{HR}=2.23 \rightarrow 95 \% \mathrm{CI}: 1.92-4.18)$, BPD $(\mathrm{HR}=1.89 \rightarrow 95 \% \mathrm{CI}: 1.59-3.07)$ and the level of maternity where birth occurred $(\mathrm{HR}=1.77 \rightarrow$ 95\%CI: 1.28-4.01). These factors could be considered as predictive factors for death of preterm neonates with GA less than 34 weeks (Table 8).

The current trend in medicine is to reduce the invasiveness of neonatal care methods. Until recently, many primary interventions in the management of premature newborns were early intubation followed by mechanical ventilation, often with $100 \%$ oxygen concentration and surfactant administration via the endotracheal tube.

\section{DISCUSSION}

Premature birth is defined as birth before 37 complete weeks of gestation or less than 259 days from the first day of the last menstrual period (WHO, 1977). Premature birth can be further subdivided according to gestational age (GA): extremely premature (GA $<28$ weeks), very premature ( $\mathrm{GA}=28-32$ weeks $)$ and moderately premature $(\mathrm{GA}=32-37$ weeks). The concept of prematurity is the combination between birth weight $(\mathrm{BW})$ and GA. If GA is a key element in prognosis, then birth weight reflects "in utero" growth, and it is an independent and additional element (WHO - Born too soon, 2012; Copetti \& Cattaross, 2007; Onland et al., 2011).

Gestational age is one of the criteria for viability of newborns. Lower gestational ages are not common, $93 \%$ of premature births occur at GA $>28$ weeks and only $6 \%$ occur at 22-27 weeks (Onland et al., 2011; Seckl, 2008; Shinwell \& EventovFriedman, 2009; van Bel \& Heijnen, 2009).
Premature infants with $\mathrm{BW} \leq 999 \mathrm{~g}$ represent less than $1 \%$ of all newborns, but their mortality rate is $50 \% .90 \%$ of them die in the neonatal period, $2 / 3$ of them die in the first 72 hours of life and only $8 \%$ of extremely small infants die after 28 days of life. According to most authors, the smallest viable gestation age is 23 weeks (Onland et al., 2011; Shinwell \& Eventov-Friedman, 2009).

In the Republic of Moldova, the percentage of premature infants with a birth weight $<1000 \mathrm{~g}$ is $0.4 \%, 0.3 \%$ in Romania, $0.7 \%$ in USA and $0.28 \%$ in Russia (Onland et al., 2011).

The mortality of premature infants is inversely related to the gestational age at birth. Premature neonates born at 23-24 weeks of gestation have a mortality rate 4 times higher than infants born at more than 28 weeks. Establishing an effective connection between the team counseling and the parents is decisive in decision making. Children born up to 32 weeks of gestation represent approximately $16 \%$ of all premature births. In all regions mortality and morbidity rates are highest especially in this group, although improved medical care led to increased survival and better long-term outcomes among children born very preterm, especially in high-income countries (Saigal \& Doyle, 2008; Wilson-Costello et al, 2005; Tsou \& Tsao, 2003). In all regions, a high percentage of neonatal deaths is mainly due to premature births, especially in lowincome countries, where there is lack even in basic assistance.

There is an extreme gap in survival indicators based on place of birth. In countries with low economic level more than $90 \%$ of children born extremely prematurely die in the first days of life, and $50 \%$ children born at 32 weeks die from lack of care of low cost and high effectiveness methods. Using appropriate neonatal intensive care, $50 \%$ of babies born at 24 weeks survive in countries with high economic level. There, death rate is less than $10 \%$ for newborns with the gestational age less than 28 weeks. Thus, the survival indicators corre-

TABLE 8. Coefficients and Wald test in multiple regression regarding risk factors in premature newborns death

\begin{tabular}{|c|c|c|c|c|c|c|c|}
\hline \multirow{2}{*}{ Risc factors } & \multirow{2}{*}{$\beta$} & \multirow{2}{*}{ S.E. } & \multirow{2}{*}{ Wald } & \multirow{2}{*}{$\begin{array}{l}\text { Sig. } \\
\text { p-value }\end{array}$} & \multirow{2}{*}{$\begin{array}{c}\text { Hazard Ratio (HR) } \\
\operatorname{Exp}(\beta)\end{array}$} & \multicolumn{2}{|c|}{$95 \% \mathrm{Cl}$ forHR - $\operatorname{EXP}(\beta)$} \\
\hline & & & & & & Lower & Upper \\
\hline GA & 6.048 & 0.035 & 1.949 & 0.0163 & 2.4049 & 1.981 & 3.123 \\
\hline BW & 9.018 & 0.019 & 7.797 & 0.0344 & 2.9018 & 2.311 & 4.058 \\
\hline Resuscitation method & 4.751 & 0.059 & 2.739 & 0.0190 & 2.2352 & 1.927 & 4.182 \\
\hline RDS & 2.047 & 0.091 & 0.620 & 0.0142 & 3.0351 & 2.026 & 4.657 \\
\hline BPD & 1.017 & 0.046 & 4.135 & 0.0271 & 1.8983 & 1.599 & 3.076 \\
\hline Maternity level & 2.002 & 0.007 & 3.099 & 0.0275 & 1.7702 & 1.289 & 4.015 \\
\hline
\end{tabular}


lation is 10: 90 . In the last decade, in some countries the mortality associated with premature birth was halved using available and inexpensive measures of care.

In 2012, according to data provided by the Ministry of Health the newborn survival rate for neonates with $\mathrm{BW}<1,000 \mathrm{~g}$ was $43.7 \%$ but in those with BW between $1,000-1,499 \mathrm{~g}$ was $\approx 80.6 \%$ versus the year 2,000, when the rate of newborns with $\mathrm{BW}<1,000 \mathrm{~g}$ was $\approx 1.64 \%$, and $52.2 \%$ in the 1000 $1499 \mathrm{~g}$ category. We should recognize that the survival of children under $1000 \mathrm{~g}$ remains low, although it increased by $35 \%$ during the last decade. Also, it must be specified that the survival of this contingent of children increased specifically after the introduction of new technologies with a high degree of efficiency in 2006 (Onland et al., 2011; Niemarkt \& Kuypers, 2014).

One of the problems of morbidity and mortality of premature newborns is home birth, when the infants do not receive essential care such as thermic control, neonatal resuscitation using contemporary methods of respiratory support and surfactant administration.

A worldwide increase in the incidence of noninfectious diseases, such as diabetes and hypertension, as well as an increased risk of premature birth associated with it, requires special attention to maternal health, including antenatal diagnosis, treatment of non-infectious diseases and other condi- tions which are known to increase the risk of premature birth.

Preterm infants have an increased risk to develop non-infectious diseases, such as diabetes and hypertension, and other serious health disorders in later periods of life (Hovi et al., 2007; Roberts \& Dalziel, 2006; Tsou \& Tsao, 2003).

\section{CONCLUSION}

Although the mortality rate of premature infants has obviously improved in the past 3-4 decades, survival of these babies remains an important issue, as they remain vulnerable to multiple complications related to prematurity.

The main factor that determines the rate of death for these infants is respiratory distress syndrome, followed by birth weight, gestational age, resuscitation method, bronchopulmonary dysplasia and last but not least, by the level of maternity where the infant was born. These factors might be considered predictive for death of preterm newborns with gestational age below 34 weeks.

LISA, a non-invasive method of surfactant administration, which currently can only be performed in level III perinatal centres, was shown to be effective in improving the general health of premature babies with improved survival indicators and with decreasing death rate and complications related to prematurity and surfactant administration.

\section{REFERENCES}

1. ACOG Committee on Obstetric Practice. ACOG Committee Opinion No. 475: Antenatal corticosteroid therapy for fetal maturation. Obstet Gynecol 2011; 117:422.

2. Aguar M., Cernada M., Brugada M. Minimally invasive surfactant therapy with a gastric tube is as effective as the intubation, surfactant, and extubation technique in preterm babies. Acta Paediatr. 2014 Jun;103(6):e229-33. doi: 10.1111/apa.12611. Epub 2014 Mar 15.

3. Copetti R., Cattarossi L. The "double lung point": an ultrasound sign diagnostic of transient tachypnea of the newborn. Neonatology 2007; 91:203.

4. David K. Stevenson, Ronald S. Cohen, Philip Sunshine. Neonatology. Clinical practice and procedures. ISBN 978-0-07176376-9. US.2015, 1415p.

5. Hovi P., Andersson S., Eriksson J.G. et al. Glucose Regulation in Young Adults with Very Low Birth Weight N Engl J Med 2007; May 356:2053-2063

6. Niemarkt H.J., Kuypers E. Effects of less-invasive surfactant administration on oxygenation, pulmonary surfactant distribution, and lung compliance in spontaneously breathing preterm lambs. 2014 Aug; 76(2):166-70. doi: 10.1038/pr.2014.66. Epub 2014 May 5.

7. Onland W., de Laat M.W., Mol B.W., Offringa M. Effects of antenatal corticosteroids given prior to 26 weeks' gestation: a systematic review of randomized controlled trials. Am J Perinatol 28 (2011) 33-44

8. P. Stratulat, Gh. Paladi, St. Gatcan. Prematuritatea: aspecte obstetricale şi neonatale. Chisinau, 2013, Chisinau - "Foxtrot", 454 p.

9. Roberts D., Dalziel S. Antenatal corticosteroids for accelerating fetal lung maturation for women at risk of preterm birth (Review) Copyright

(c) 2006 The Cochrane Collaboration. Published by John Wiley \& Sons, Ltd

10. Saigal S., Doyle L.W. An overview of mortality and sequelae of preterm birth from infancy to adulthood. Lancet. 2008 Jan 19;371(9608):261-9.

11. Seckl J.R. Glucocorticoids, developmental, programming' and the risk of affective dysfunction. Prog Brain Res. 167(2008)17-34.

12. Shinwell E.S., Eventov-Friedman S. Impact of perinatal corticosteroids on neuromotor development and outcome: Review of the literature and new meta-analysis. Seminars in Fetal Neonatal Med 14 (2009) 164-170

13. Tsou K.I., Tsao P.N. Taiwan Infant Development Collaborative Study G. The morbidity and survival of very-low-birth-weight infants in Taiwan. Acta Paediatr Taiwan. 2003; 44(6):349-55.

14. van Bel F., Heijnen C.J. Perinatal programming and reprogramming by glucocorticoid therapy and perinatal stress Seminars ma Fad Neonatal Med 14 (2009) 127-129

15. WHO, March of Dimes, Partnership for Maternal, Newborn \& Child Health, Save the Children. Born too soon: the global action report on preterm birth. www.who.int/maternal_child_adolescent/documents/ born_too_soon/en/ (Accessed on May 04, 2012).

16. Wilson-Costello D., Friedman H., Minich N., Fanaroff A.A., Hack M. Improved survival rates with increased neurodevelopmental disability for extremely low birth weight infants in the 1990s. Pediatrics. 2005; 115(4):997-1003. doi: 10.1542/peds.2004-0221. 